\title{
EVALUATION OF THE INTERNATIONAL PROGRAMME PORTFOLIO OF THE AUSTRIAN SCIENCE FUND (FWF)
}

ALEXANDER DEGELSEGGER-MÁROUEZ, ISABELLA WAGNER, JOHN RIGBY AND DEBORAH COX

\section{INTRODUCTION}

$\mathrm{T}$ his article presents a summary of the evaluation of the international programme portfolio of the Austrian Science Fund (FWF), which was carried out between June 2016 and September 2017. We assessed the suitability of the portfolio in terms of supporting international cooperation in line with FWF's mandate. We also assessed programme design and management. In addition, we traced evidence for the impact of the international programmes. The evaluation provides results that are relevant for understanding programmatic options to support international cooperation. The results also support FWF's strategic decision-making on future programme design.

In the following, we introduce the context of the evaluation, then focus on its methodology, and finally present and discuss selected results.

\section{SPECIFICITIES OF A DEDICATED EVALUATION OF AN INTERNATIONAL PROGRAMME PORTFOLIO}

\footnotetext{
The study was implemented against a background of:

- a general rise in international research cooperation that is well documented in bibliometrics and research policy literature (e.g. Science Europe/Elsevier 2013; Royal Society 2011); and

- the increased importance of international cooperation for small research systems like Austria. (cf. OECD 2017, 124).
}

In recent years, international cooperation has not only been acknowledged as a relevant trend in academic research, but has also attracted the attention of policy-makers and research funders, who aim to shape and support the way researchers cooperate. Their rationales to do so can lie within or outside the realm of science (Boekholt et al. 2009). Some support internationalisation primarily as a means to research excellence or knowledge access, others consider it an avenue towards competitiveness or for science diplomacy reasons. On occasions, both perspectives are combined in one instrument.

Even when research funders are independent from research policy and follow a narrow mandate to support the best science, like in the case of FWF, they have to decide on the ways in which international cooperation is supported: explicitly/implicitly, thematically bottom-up/top-down, with whom, in what geographic areas, etc. This is all the more important if the funding agency has a high systemic relevance, like in the case of FWF in Austria.

In the period of the study (project funding decisions between 20032015), FWF supported international cooperation through a portfolio of instruments, including:

- support for research projects (i.e. including personnel costs) in bilateral and multilateral schemes: bilateral joint programmes, bilateral and multilateral lead agency ${ }^{1}$ programmes, multilateral ERA-Net programmes, multilateral Eurocores programmes, and;

- networking support in bilateral and multilateral settings.

In addition, there is the possibility of including international cooperation in FWF's regular stand-alone research projects. FWF's dedicated mobility programmes (Schrödinger and Meitner scholarships) were not part of the current analysis.

Between 2003 and 2015, FWF invested slightly over $€ 134 \mathrm{~m}$ in its international programmes (14\% of its overall budget in the most recent years). This makes it the most significant funder of international research cooperation in Austria, and the only one with funds for thematically open international research projects. The largest share of this sum was invested through Lead Agency procedures (€ 65.70m, 49.8\%; 9 programmes). $€ 32.96 \mathrm{~m}$ were invested in ERA-Nets (21 ERA-Nets, 52 Calls), $€ 18.92 \mathrm{~m}$ in bilateral non-lead agency joint programmes (11 programmes) and $€$ $16.68 \mathrm{~m}$ went into EUROCORES Calls (29 Calls).

An overview on the project structure and their start dates can be viewed in Figure 1. 


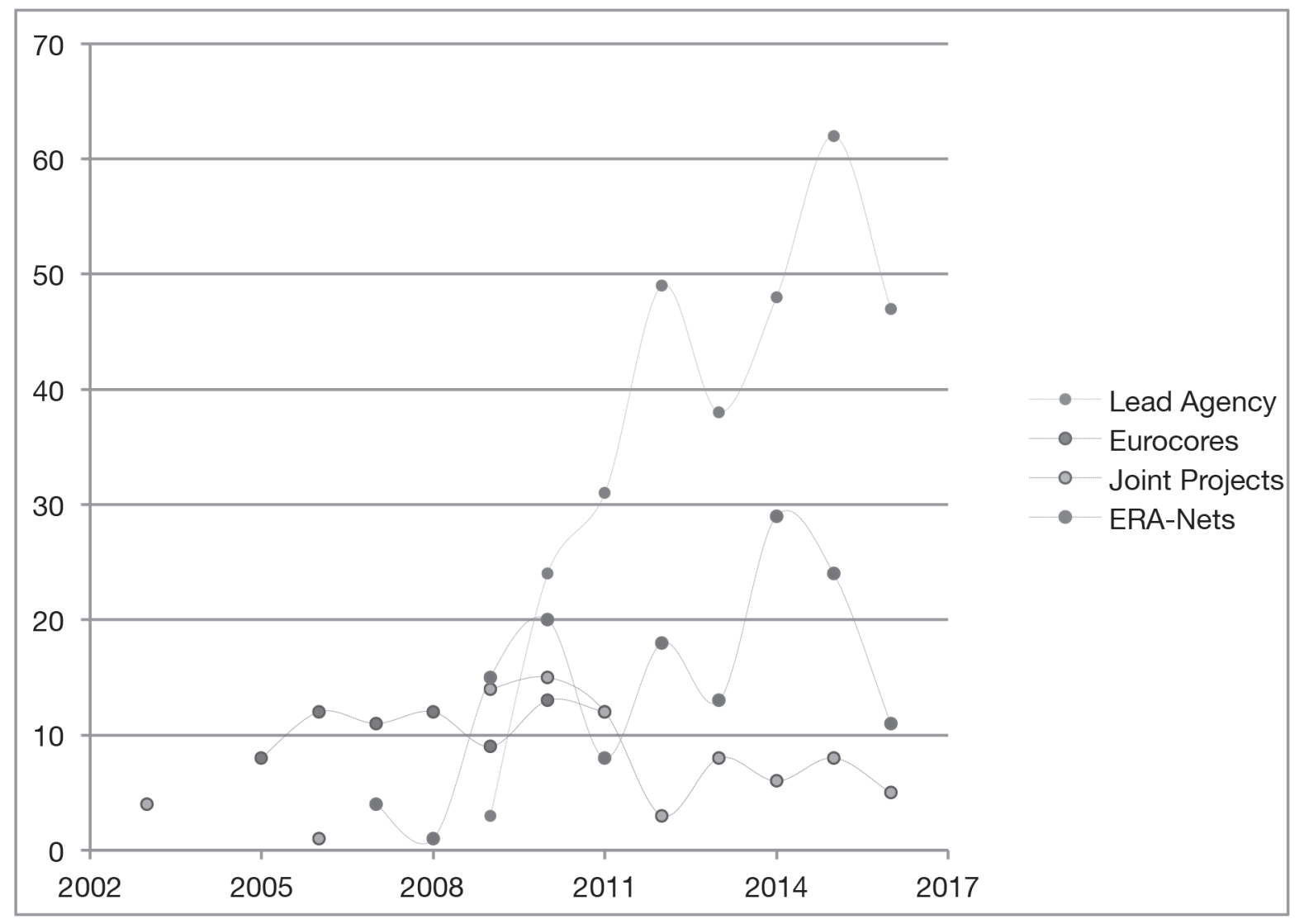

Figure 1: FWF project start dates for 4 international programme types from 2003-2016 (funding decisions 2003-2015)

The present evaluation study is unique in the sense that it is the first to assess the effects and performance of a dedicated international programme portfolio. There have been evaluations of international research cooperation programmes (e.g. ZSI's evaluation of the Austrian scientific and technological cooperation agreements or the German BMBF's Baltic Sea programme). However, the additionality of specific international cooperation support programmes, for example regarding cooperation intensity, impact and sustainability, compared to other forms of enabling international cooperation (e.g. through the FWF stand-alone projects) is novel territory.

\section{METHODOLOGY}

In order to do justice to this unique evaluation setting and to address the evaluation questions as specified in the terms of reference, we designed a mixed method approach, combining quantitative and qualitative elements: descriptive programme statistics, bibliometrics and altmetrics, provided quantitative data; interviews, a focus group and a scenario workshop added qualitative insights. A beneficiary survey, secondary data analysis of a previous survey-based study, as well as an analysis of final reports provided both qualitative and quantitative evidence. These methods were integrated in various ways, for instance:

- The secondary data analysis of a previous comprehensive FWF beneficiary survey helped to check the validity of survey and programme data-based conclusions on the beneficiary population.

- Project report data was combined with survey data to extract evidence on the intensity and sustainability of the supported cooperation.

- Survey data has been triangulated with programme data to assess additionality in terms of the geographical scope of supported cooperation.

- Survey and interview data was analysed and prepared as an input for focus group discussions on the appropriateness and possible futures of the international programme portfolio.

To assess the additionality and impact of the international programme portfolio compared to other forms of supporting international cooperation, we used statistical matching techniques to construct a comparison group out of FWF-supported stand-alone projects. Statistical pairs were selected on the basis of the following variables: start date of the project, gender and age of the Principal Investigator (PI), discipline, budget of the project. The comparison group approach was implemented both in the bibliometric analysis as well as in the beneficiary survey.

Table 1 provides an overview of how the different methodological strands contributed to the evidence for responding to each evaluation question. 


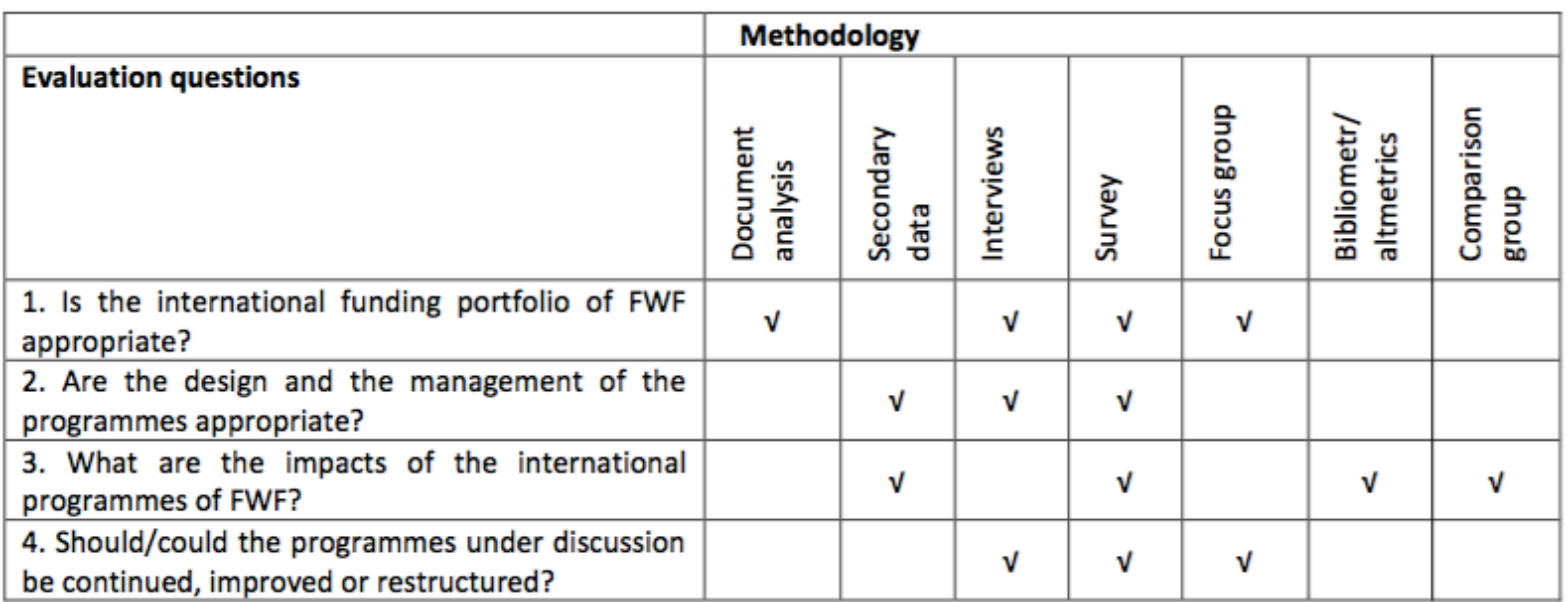

Table 1: Methods and evaluation questions

\section{SELECTED RESULTS}

The present evaluation study provided evidence for the suitability of FWF's international cooperation programme portfolio and its additionality vis-à-vis other forms of supporting international cooperation.

FWF's international programmes mobilise and, thus, support a segment of the Austria-based research community that goes beyond FWF's regular beneficiaries (e.g. in stand-alone projects). $48 \%$ of Principal investigators (PIs) in international programme-supported projects have only had FWF support in this type of projects (one or several times). Pls in international programme-supported projects are well-established scientists, more frequently in professor positions and with unlimited contracts, than their peers working on stand-alone projects. The Pls in international programme-supported projects are, on average, 48.3 years old (at project start). Young researchers use different programmes for international cooperation. Many of the Pls have experience with other international cooperation support programmes and have had one or several long-term mobility experiences. However, the geographic patterns of cooperation in international programmes are not predetermined by Pls' personal background (nationality) or mobility experiences. We conclude that FWF's international programmes contribute significantly to the internationalisation of science in Austria.

Additionality to other national as well as European funding schemes is given. The thematically open funding of collaborative research projects is a particularly unique aspect of FWF's portfolio. Collaborative funding in the EU Framework Programmes is thematically pre-defined. Thematically open funding through the ERC is oriented at individuals. In the Austrian context, international cooperation is also widely practiced in thematically open FWF-supported stand-alone projects, international cooperation is also widely practiced in FWF-supported stand-alone projects. However, the intensity of the cooperation is higher in the international projects, compared to stand-alone FWF projects. The geographies of cooperation are also slightly different: cooperation with researchers in emerging economies is almost exclusively facilitated by international programmes. The geographical additionality can also be seen when comparing the international programme project funding with the mobi- lity funding in the Schrödinger fellowships. Over half of the Schrödinger fellows between 2011 and 2015 go to either the US or the UK. Only 2\% of Schrödinger fellows go to France, a country that makes up $25 \%$ of the international programme-funded projects. Collaboration with Spain or the Czech Republic is also practiced mostly in an international programmefunded projects.

In terms of impact additionality, our bibliometric analyses show consistently higher-than-average field-normalised citation impacts of publications in international programme-supported projects compared to stand-alone projects. This result is stable over the different disciplines. With some variation among regions (slightly lower citation impacts for publications with authors in emerging economies), the above-average citation rates are also geographically stable.

The sustainability of the cooperation brought about by international programmes can only partly be assessed at this time, as the largest share of international programme-supported projects have only started in recent years. Turning to the beneficiaries' views, a majority of survey respondents indicates that they continued their cooperation beyond the international programme support. The analysis of publication histories suggests that international projects either help to continue existing cooperation patterns, or to induce new ones. There is no evidence for Pl's disrupting cooperation with colleagues in a certain country.

Beneficiary satisfaction with programme management and related processes is high. The various instruments are in demand and, although success rates are lower than stand-alone projects, they are still considered adequate by most. The beneficiaries are also satisfied with the international programme portfolio. $40 \%$ of our survey respondents consider their need for international cooperation support is met by current programmes, while $49 \%$ see it partially met. When asked in what regions international cooperation would be important, but is difficult to implement with the current instruments, beneficiaries point to countries with strong research systems (EU, USA, Canada, Japan, Korea, Australia) as well as the BRICS countries. In terms of instruments, geographically and thematically open support for multilateral cooperation, as well as networking support, are in demand as an expansion of the portfolio.

\section{DISCUSSION}


With the help of the evidence collected, we have facilitated discussions on future scenarios for the international programme portfolio. There is no evidence suggesting a discontinuation or a complete overhaul of the international programmes is needed. Instead, there is strong evidence and demand for the continuation of the portfolio in a slightly adjusted form. We suggest a combination of:

- the continuation of the portfolio, including selected country strategies, without a fragmentation into too many small programmes;

- the continuation of FWF's push for multilateral, thematically open funding approaches (which depend on the capacities and interest of the other funding parties) e.g. in a European context; and

- the exploration of an FWF-funded networking scheme.

In each evaluation, there are questions that must remain open because of limits of scope or data availability. One of the most interesting and relevant questions to consider in this regard, is the age structure of Pls in international programmes. Also, at the time of the present evaluation, due to the increase of international programme-supported projects in recent years, longitudinal data were available only to a limited extent. This affects the qualitative and quantitative assessment of the sustainability of cooperation. It also affects citation impact analysis as many recently funded projects are only starting to produce publications.

We have stated at the outset that the evaluation of a research funding agency's international programme portfolio is novel territory. There is currently no possibility to carry out a cross-country comparison of the effectiveness and efficiency of international cooperation support. The data available for comparison are scarce and general. Among the few available data are, for instance, information on the budget shares of international cooperation programmes. In order to shed further light on the question of how research funders can best stimulate international cooperation, more in-depth comparative data on programme outputs and outcomes are necessary.

\section{REFERENCES}

Boekholt, P. et a. (2009): Drivers of International collaboration in research. Final Report, Brussels: Technopolis/MIOIR, online: https:// ec.europa.eu/research/evaluations/pdf/archive/other_reports_studies_ and_documents/drivers_of_international_coop eration_in_research. pdf.

OECD (2017): OECD Science, Technology and Industry Scoreboard: The Digital Transformation, online: http://www.oecd.org/sti/scoreboard. htm, accessed: 3 July 2018.

Royal Society (2011): Knowledge, Networks and Nations: Global Scientific Collaboration in the 21st Century, London: Royal Society.

Science Europe / Elsevier (2013): Comparative Benchmarking of European and US Research Collaboration and Researcher Mobility. A report prepared in collaboration between SciVal Analytics September, http:// www.scienceeurope.org/uploads/PublicDocumentsAndSpeeches/SE_ and_Elsevier_Report_Final.pdf.

\section{More information and access to the evaluation report:}

https://repository.fteval.at/332/

https://www.fwf.ac.at/de/news-presse/news/nachricht/nid/20180423$\underline{2294 /}$

https://www.zsi.at/en/object/project/4209

https://zenodo.org/record/1194558\#.Wz9SIGf-Urq

Selected quantitative data generated in this study are being published via the Austrian Social Science Data Archive ${ }^{2}$ for further scientific usage.

\section{AUTHORS}

\section{ALEXANDER DEGELSEGGER-MÁROUEZ ISABELLA WAGNER}

\section{Centre for Social Innovation (ZSI)}

Linke Wienzeile 246,

1150 Vienna, Austria

E: degelsegger@zsi.at

E: wagner@zsi.at

\section{JOHN RIGBY \\ DEBORAH COX}

Manchester Institute of Innovation Research

Oxford Road, Manchester, M13 9PL, United Kingdom

E: John.Rigby@manchester.ac.uk

Other contributors to the evaluation study:

Sybille Hinze and Paul Donner | Deutsches Zentrum für Hochschul- und Wissenschaftsforschung

Jonathan Adams | Digital Science

\section{ACKNOWLEDGEMENTS}

The study was funded by the Austrian Science Fund. The evaluation team thanks the FWF for their excellent cooperation. We are particularly grateful for the support and process management by Klaus Zinöcker, whose untimely passing away came as a shock to the team. 